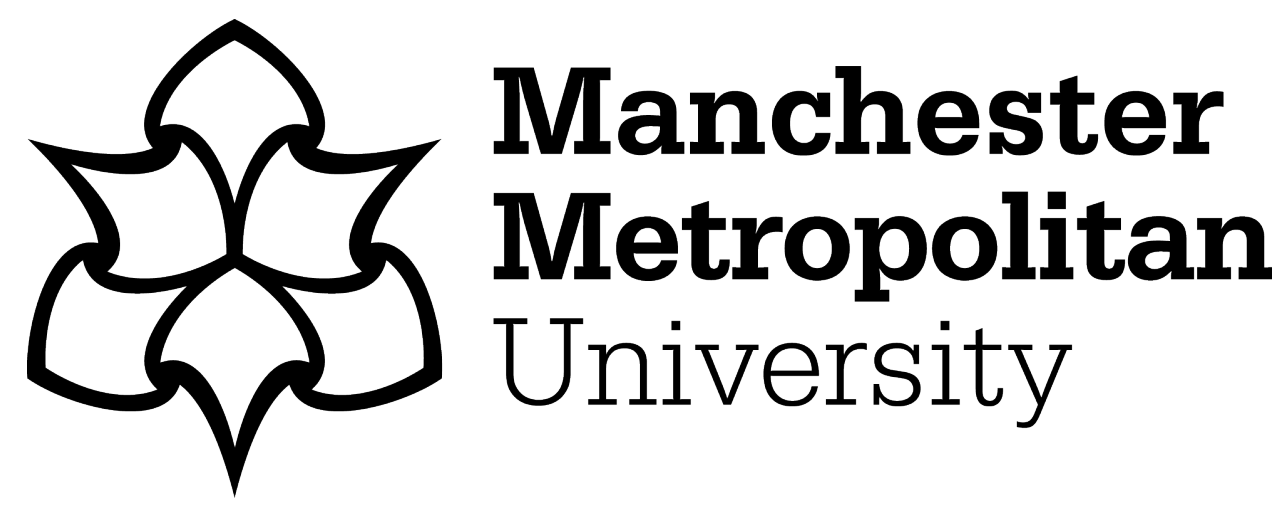

Hickey, Niall A, Whitehead, Kathryn A, Shalamanova, Liliana, Butler, Jonathan A and Taylor, Rebecca $L$ (2019) A novel microbiological medium for the growth of periodontitis associated pathogens. Journal of Microbiological Methods, 163. p. 105647. ISSN 0167-7012

Downloaded from: https://e-space.mmu.ac.uk/623107/

Version: Accepted Version

Publisher: Elsevier

DOI: https://doi.org/10.1016/j.mimet.2019.105647

Usage rights: Creative Commons: Attribution-Noncommercial-No Derivative Works 4.0

Please cite the published version 


\section{A novel microbiological medium for the growth of periodontitis associated pathogens} Niall A. Hickey ${ }^{1}$, Kathryn A. Whitehead ${ }^{1}$, Liliana Shalamanova ${ }^{1}$, Jonathan A. Butler ${ }^{1}$ and Rebecca L. Taylor $^{1 *}$

${ }^{1}$ Department of Life Sciences, Faculty of Science and Engineering, Manchester Metropolitan University, Chester Street, Manchester M1 5GD, UK.

*To whom correspondence should be addressed. Email: r.taylor@mmu.ac.uk;

\section{Highlights}

- A novel growth medium for culturing periodontal pathogens

- More representative of the periodontal environment

- Cultivates a selection of periodontal pathogens and can be used with human cell culture

\section{Abstract}

A novel microbiological medium designed to be more representative of gingival crevicular fluid. Chosen representative periodontal microorganisms showed good growth with minimal effect on human cell viability. This will enable more comparisons between different periodontitis associated organisms and their potential role in host health and systemic disease.

Keywords: Chronic Periodontitis, Growth Medium, Oral Microbiology, Cell Culture

Chronic Periodontitis (CP), an infection of the periodontium, leading to the formation of periodontal pockets and tooth loss if untreated (1). It is the most common infectious inflammatory disease worldwide affecting humans (2) with $45 \%$ of English adults having at least one periodontal pocket (3). CP is of particular interest as it can be detrimental to the health of the patient and a risk factor for myriad diseases such as Alzheimer's, (4) cardiovascular disease (5) and diabetes mellitus (6). Subgingival bacteria are the main aetiological agents behind the inflammatory processes seen in CP and induce dysregulation of the normal oral microbiota (7) and an increased flow of gingival crevicular fluid (GCF), an inflammatory exudate that bathes the gingival crevice and favours the growth of anaerobic periodontal microorganisms (8). A key contributor to CP is Porphyromonas gingivalis (9), however, it appears that no singular group of organism is responsible for causing CP and it is likely that polymicrobial synergy and dysbiosis of multiple periodontitis associated pathogens play a role in modulation of the disease (10). Many of these periodontitis associated pathogens are difficult to culture in vitro, which is partly compounded by the lack of available broad host growth media. Periodontal pathogens are usually fastidious anaerobes and rely on nutrients secreted by other bacteria during synergism along with specific microbial and non-microbial nutrient sources (11). The aim of this study was to develop a growth medium that can facilitate the culture of a wide selection of periodontitis associated microorganisms and enable further study of potential systemic disease links via tissue culture based investigations. With the growth requirements of many of these organisms being specifically evolved to the unique environment of the gingival crevice, emulating components of the GCF can allow a developed medium to be more representative of this environmental interface and allow more representative growth of periodontal microorganisms.

Bacterial strains were maintained in growth media as recommended by the manufacturer. Actinomyces israelii (NCTC 12972), Campylobacter showae (NCTC 12843), Fusobacterium nucleatum subsp. Fusiforme (11326) and Prevotella intermedia (NCTC 13070)were cultivated in anaerobic conditions $\left(80 \% \mathrm{~N}_{2}-10 \% \mathrm{H}_{2}-10 \% \mathrm{CO}_{2}\right.$ ) in a Baker-Ruskin Concept Plus anaerobic incubator (Ruskin, UK) at $37^{\circ} \mathrm{C}$ for 48 h. P. gingivalis (NCTC 11834) was cultivated in an anaerobic incubator for $72 \mathrm{~h}$. Rothia dentocariosa (10917), Streptococcus constellatus (NCTC 11325) and Streptococcus sanguinis (NCTC 7863) were cultivated in carbon rich conditions $\left(5 \% \mathrm{CO}_{2}\right)$ in a $\mathrm{CO}_{2}$ incubator (LEEC, UK) at $37^{\circ} \mathrm{C}$ for $48 \mathrm{~h}$.

The base medium utilised was Basal Medium Mucin (BMM) as it has successfully been shown to emulate saliva for the growth of dental plaque biofilms in an 'artificial mouth' system (12). The constituents of BMM contained: $2.5 \mathrm{~g} / \mathrm{L}$ partially purified pig gastric mucin, $10 \mathrm{~g} / \mathrm{L}$ proteose peptone, $5 \mathrm{~g} / \mathrm{L}$ trypticase 
peptone, $5 \mathrm{~g} / \mathrm{L}$ yeast extract, $2.5 \mathrm{~g} / \mathrm{L} \mathrm{KCl}, 1 \mathrm{mMol} / \mathrm{L}$ urea, $1 \mathrm{mMol} / \mathrm{L}$ arginine, $1 \mathrm{mg} / \mathrm{L}$ of haemin and $1 \mathrm{mg} / \mathrm{L}$ of menadione, all purchased from Sigma Aldrich, UK.

The new growth medium, Artificial Gingival Crevicular Fluid - Periodontal (AGCF-P) was composed of BMM with multiple modifications. From BMM, $1 \mathrm{mg} / \mathrm{mL}$ of haemin and menadione were omitted and 5 $\%$ horse blood (TCS Biosciences) was added once cooled to $50^{\circ} \mathrm{C}$ after sterilisation by autoclave. This was designed to emulate the inorganic and organic constituents of GCF which are notably similar to plasma, as infiltration and degradation of red blood cells occurring during $\mathrm{CP}$ (13). The $\mathrm{pH}$ of the medium was adjusted to reflect the actual $\mathrm{pH}$ of GCF during $\mathrm{CP}(7.96 \pm 0.1)$ (14). Buffering of $\mathrm{pH}$ was performed using the phosphate buffer system of Potassium Phosphate monobasic anhydrous and Sodium Phosphate dibasic heptahydrate. Cysteine was added as a reducing agent to further mimic the reducing capacity and support the growth of anaerobic organisms. The full composition of AGCF-P was: $10 \mathrm{~g} / \mathrm{L}$ proteose peptone, $5 \mathrm{~g} / \mathrm{L}$ trypticase peptone, $5 \mathrm{~g} / \mathrm{L}$ yeast extract, $2.5 \mathrm{~g} / \mathrm{L} \mathrm{KCl}, 2.5 \mathrm{~g} / \mathrm{L}$ partially purified pig gastric mucin, $0.5 \mathrm{~g} / \mathrm{L}$ L-cysteine, $0.17 \mathrm{~g} / \mathrm{L}$ L-arginine, $0.18 \mathrm{~g} / \mathrm{L} \mathrm{L}$-urea, $1.68 \mathrm{~g} / \mathrm{L}$ Potassium Phosphate monobasic anhydrous, $41.31 \mathrm{~g} / \mathrm{L}$ Sodium Phosphate dibasic heptahydrate and $5 \%$ horse blood. If creating solid media $12 \mathrm{~g} / \mathrm{L}$ of agar no 3 was added. All reagents were procured from Sigma Aldrich, UK with the exception of trypticase peptone (Scientific Laboratory Supplies, UK) and horse blood.

The growth of the bacterial strains on AGCF-P agar was determined by streaking a single isolated colony onto an AGCF-P agar plate. This plate was sub-cultured again to ensure continuity and photographed (not shown). Growth of bacterial strains in liquid culture was tested by inoculating a single colony into $5 \mathrm{~mL}$ of AGCF-P broth and grown for the NCTC recommended duration; growth was demonstrated by inoculating an AGCF-P agar plate and further incubation. For growth curves, three overnight cultures of the chosen microorganism were adjusted to an absorbance of $1.0 \pm 0.05$ at $540 \mathrm{~nm}$ obtained using a spectrophotometer (Jenway, UK). One millilitre per $100 \mathrm{~mL}$ of culture was inoculated into three sterile culture flasks with liquid AGCF-P growth media equilibrated overnight. Growth was assessed at 0, 2, 4, 6, 24 , and $48 \mathrm{~h}$ or daily for 5 day for $P$. gingivalis and at each time point colony forming units per $\mathrm{mL}$ $(\mathrm{CFU} / \mathrm{mL}$ ) were quantified using the Miles-Misra droplet method and viability was determined (15).

Human Gingival Fibroblast (HGF-1) primary cells (LGC standards, UK) were cultured in Dulbecco Modified Eagle Medium (DMEM) with Glutamine and Glucose (Lonza, UK), supplemented with $10 \%$ foetal calf serum (Lonza, UK), $50 \mathrm{\mu g} / \mathrm{mL}$ streptomycin (Lonza, UK) and $50 \mu \mathrm{g} / \mathrm{mL}$ penicillin (Lonza, UK). Immortalised Human Kidney Proximal Tubule cells (HK-2) (ATCC, UK) were cultured in 50:50 glucose free DMEM (Invitrogen, UK) and Hams F-12 medium (Lonza, UK) supplemented with $10 \%$ foetal calf serum (Lonza, UK), $50 \mu \mathrm{g} / \mathrm{mL}$ streptomycin (Lonza, UK), $50 \mu \mathrm{g} / \mathrm{mL}$ penicillin (Lonza, UK) and $2.5 \mathrm{mMol}$ glutamine (Lonza, UK). Cells were growth-arrested in serum free cell culture media, in the absence of foetal calf serum.

To assess the effect of AGCF-P bacterial growth medium on mammalian cell viability, the AGCF-P medium was incubated for 5 days in anaerobic conditions without bacterial inoculation. At $0,1,2,3,4$ and 5 days aliquots of the AGCF-P medium were plated out to check for bacterial contamination. Viability testing and statistical analysis was conducted as detailed in (16).

The growth of periodontal associated pathogens was assessed in liquid and solid AGCF-P media by inoculation or streaking with a single colony of the chosen organisms. A. israelii, C. showae, $F$. nucleatum subsp. Fusiforme, P. intermedia, P. gingivalis, R. dentocariosa, S. constellatus and S. sanguinis all showed good growth in liquid and solid cultures even with multiple subcultures (data not shown). Growth curves of representative examples of periodontal pathogens were conducted in AGCF-P broth over 2 or 5 days for $P$. gingivalis, to demonstrate growth (Figure 1 ). All organisms reached a good level of growth after $24 \mathrm{~h}$, averaging at $10^{7} \mathrm{CFU} / \mathrm{mL}$ indicating that the media was sufficiently nutritious to support the representative selection of periodontal microorganisms. 


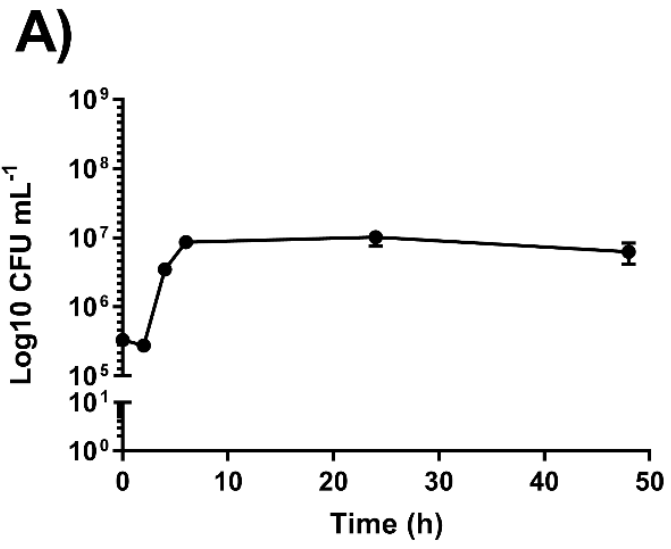

C)

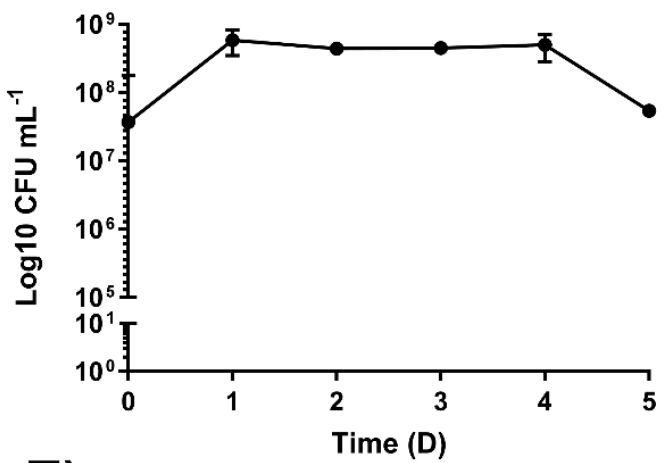

E)

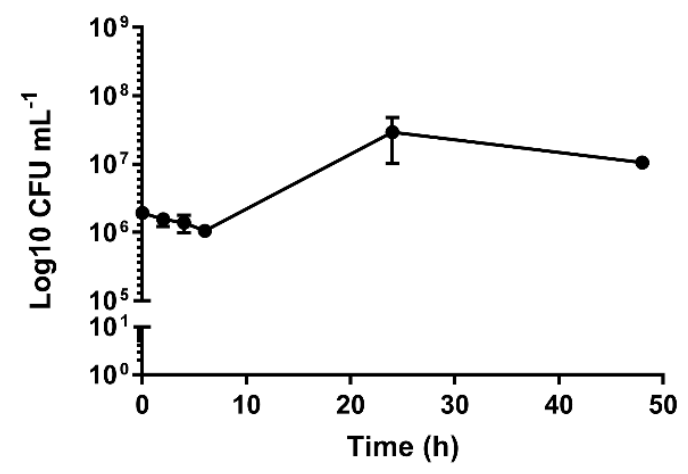

B)

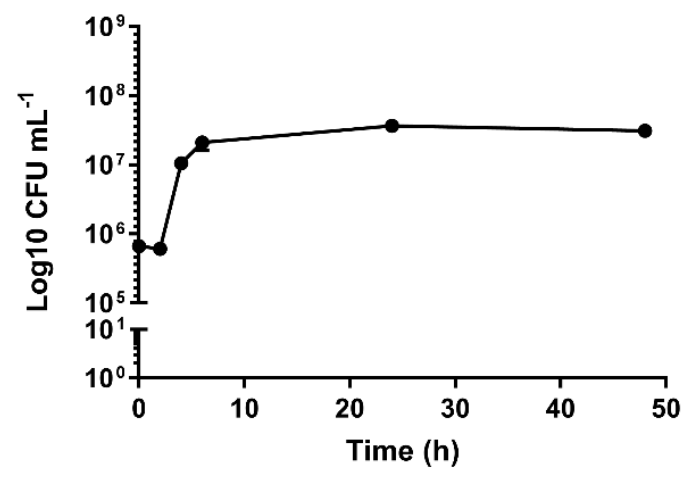

D)

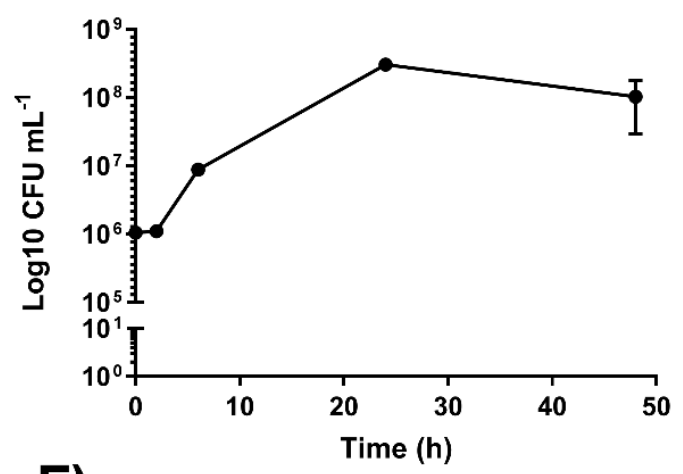

F)

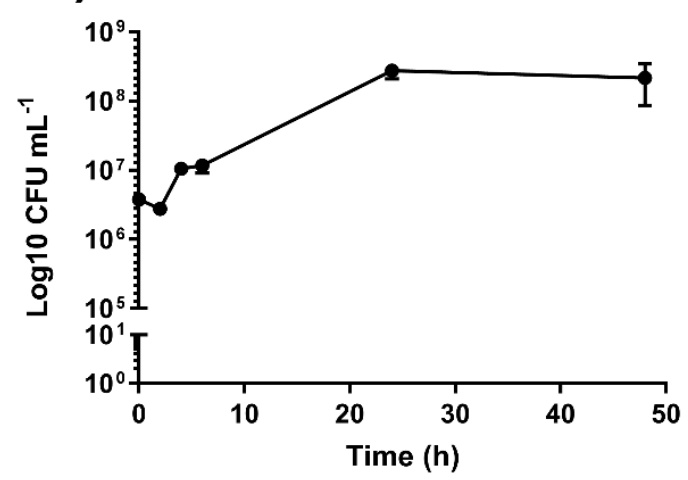

Figure 1. Growth curves of periodontitis associated pathogens cultured in AGCF-P broth. A) Actinomyces israelii B) Fusobacterium nucleatum C) Parvimonas micra D) Porphyromonas gingivalis E) Streptococcus constellatus F) Streptococcus sanguinis $(n=3)$.

The effect of the AGCF-P medium on the cell viability of HGF-1 (Figure 2), and HK-2 (Figure 3) was assessed by exposing the cells to 1:20 dilutions of AGCF-P supernatants incubated over a 5-day period in anaerobic conditions. Although the cell viability of HGF-1 was slightly increased (Figure 2), there was no significant effect of AGCF-P supernatants on the viability of these cells or HK-2 cells after $24 \mathrm{~h}$ (Figure $2 \mathrm{~A}$ and $3 \mathrm{~A}$ ) or $48 \mathrm{~h}$ (Figure $2 \mathrm{~B}$ and $3 \mathrm{~B}$ ) of incubation, as compared to control cells exposed to serum-free cell culture medium only. The mild positive effect of AGCF-P on the viability of primary gingival fibroblasts can be attributed to an increased cell proliferation due to nutrients provided by AGCF-P. 
A)

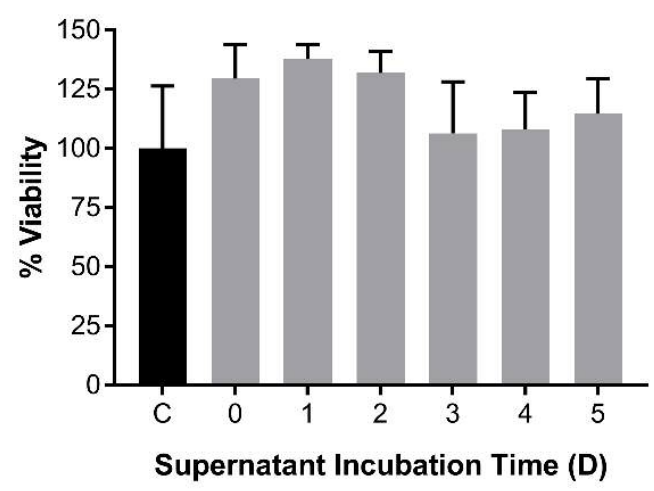

B)

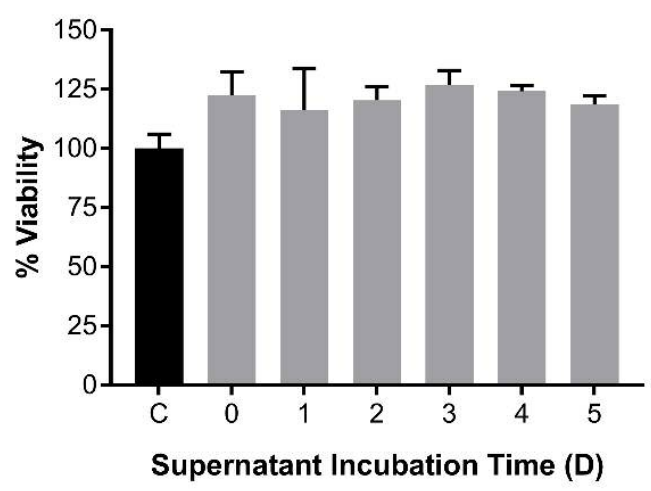

105

106

107

108

Figure 2. Cell viability of HGF-1 cells after $24 \mathrm{~h}$ (A) or $48 \mathrm{~h}$ (B) of incubation with 1:20 dilutions of AGCF-P supernatants collected over 5 days. Viability is presented as percentage change from the control (C: cells exposed to serum-free cell culture medium) and error bars represent SEM $(n=3)$.

A)

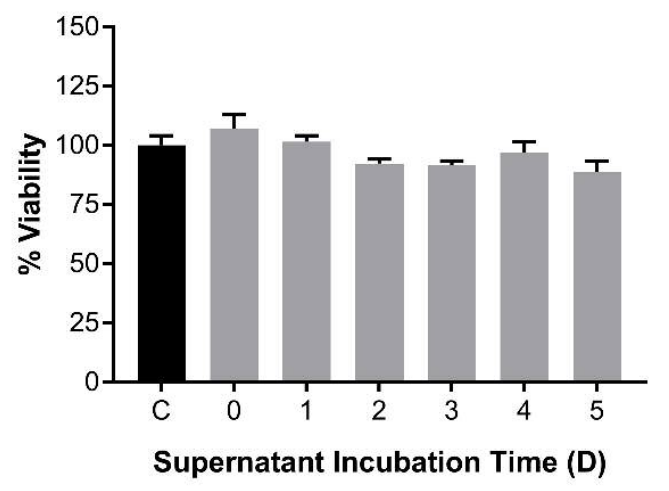

B)

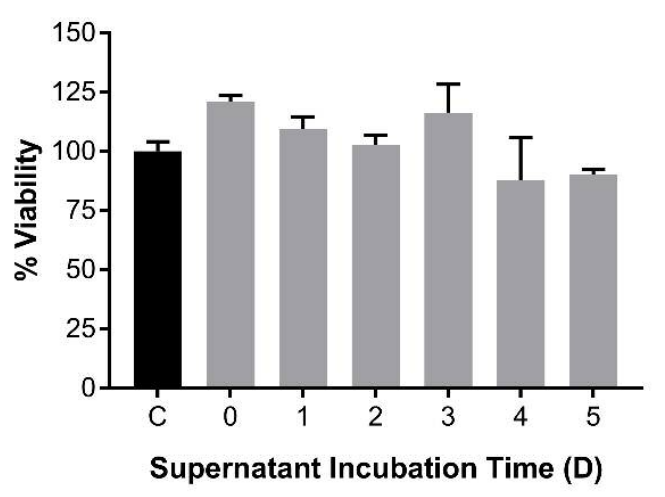

Figure 3. Cell viability of HK-2 cells after $24 \mathrm{~h}$ (A) or $48 \mathrm{~h}$ (B) of incubation with 1:20 dilutions of AGCF-P supernatants collected over 5 days. Viability is presented as percentage change from the control (C: cells exposed to serum-free cell culture medium) and the error bars represent $\operatorname{SEM}(n=3)$.

Mimicking the chemical components of the physiological environment is a successful strategy that has been used to cultivate particularly fastidious or uncultivatable organisms and also can influence the bacterial products present (17). Emulating some of the elements of the GCF should allow for more representative growth of disease-related organisms as alternative nutrient sources available may stimulate regulatory changes in gene expression profiles leading to the production of environment specific bacterial products, such as metabolites and secreted proteins (18). AGCF-P has been shown to cultivate a selection of periodontal organisms and could be used to test their secreted products in human cells without the growth media confounding the results, facilitating the development of in vitro and ex vivo models of $\mathrm{CP}$. The production of more biologically relevant conditions furthers research into the pathogenesis of $\mathrm{CP}$, enabling wide-ranging comparisons between organisms to identify key microbial products and their effect on the human host.

Funding: This research did not receive any specific grant from funding agencies in the public, commercial, or not-for-profit sectors.

Conflicts of Interest:The authors report no conflict of interest.

\section{References}

1. Hajishengallis G. Periodontitis: from microbial immune subversion to systemic inflammation. Nat Rev Immunol. 2015;15(1):30-44. 
$131 \quad 3 . \quad$ Heidari E, Banerjee A, Newton JT. Oral health status of non-phobic and dentally phobic individuals; a secondary analysis of the 2009 132 Adult Dental Health Survey. Br Dent J. 2015;219(9):E9.

133 4. Stein PS, Steffen MJ, Smith C, Jicha G, Ebersole JL, Abner E, et al. Serum antibodies to periodontal pathogens are a risk factor for 134 Alzheimer's disease. Alzheimers Dement. 2012;8(3):196-203.

135 5. Dietrich T, Jimenez M, Krall Kaye EA, Vokonas PS, Garcia RI. Age-Dependent Associations Between Chronic Periodontitis/Edentulism 136 and Risk of Coronary Heart Disease. Circulation. 2008;117(13):1668

1376 6. Engebretson SP, Hyman LG, Michalowicz BS, et al. The effect of nonsurgical periodontal therapy on hemoglobin a1c levels in 138 persons with type 2 diabetes and chronic periodontitis: A randomized clinical trial. JAMA. 2013;310(23):2523-32.

139 7. Wahid A, Chaudhry S, Ehsan A, Butt S, Ali Khan A. Bidirectional Relationship between Chronic Kidney Disease \& Periodontal Disease.

140 Pak J Med Sci. 2013;29(1):211-5

141 8. Winning L, Patterson CC, Cullen KM, Stevenson KA, Lundy FT, Kee F, et al. The association between subgingival periodontal 142 pathogens and systemic inflammation. J Clin Periodontol. 2015;42(9):799-806.

$1439 . \quad$ Wade WG. The oral microbiome in health and disease. Pharmacol Res. 2013;69(1):137-43.

$144 \quad$ Hajishengallis G, Lamont RJ. Beyond the red complex and into more complexity: the polymicrobial synergy and dysbiosis (PSD)

145 model of periodontal disease etiology. Mol Oral Microbiol. 2012;27(6):409-19.

146 11. Sharma A. Virulence mechanisms of Tannerella forsythia. Periodontol 2000. 2010;54(1):106-16

147 12. Wong L, Sissions $\mathrm{CH}$. A comparison of human dental plaque microcosm biofilms grown in an undefined medium and a chemically

148 defined artificial saliva. Arch Oral Biol. 2001;46(6):477-86.

149 13. Ferguson DB. Oral Bioscience: Authors Online Limited; 2006.

150 14. Bickel M, Munoz JL, Giovannini P. Acid-base properties of human gingival crevicular fluid. J Dent Res. 1985;64(10):1218-20.

151 15. Miles AA, Misra SS, Irwin JO. The estimation of the bactericidal power of the blood. Epidemiol Infect. 1938;38(6):732-49.

$15216 . \quad$ Slate AJ, Shalamanova L, Akhidime ID, Whitehead KA. Rhenium and Yttrium ions as antimicrobial agents against multidrug resistant

153 Klebsiella pneumonia and Acinetobacter baumanii biofilms. Letters in applied microbiology. 2019.

154 17. Vartoukian SR, Palmer RM, Wade WG. Strategies for culture of 'unculturable' bacteria. FEMS microbiology letters. 2010;309(1):1-7.

155 18. Balleza E, López-Bojorquez LN, Martínez-Antonio A, Resendis-Antonio O, Lozada-Chávez I, Balderas-Martínez YI, et al. Regulation by 156 transcription factors in bacteria: beyond description. FEMS Microbiol Rev. 2009;33(1):133-51. 